\title{
Extinction after retrieval: Effects on the associative and nonassociative components of remote contextual fear memory
}

\author{
Marco Costanzi, ${ }^{1,2}$ Sara Cannas, ${ }^{1,2}$ Daniele Saraulli, ${ }^{1,2}$ Clelia Rossi-Arnaud, $^{3}$ \\ and Vincenzo Cestari ${ }^{1,2,4}$ \\ ${ }^{1}$ CNR - National Research Council of Italy (Cell Biology and Neurobiology Institute-IBCN)/IRCCS Fondazione Santa Lucia, Rome \\ 00143, Italy; ${ }^{2}$ Faculty of Educational Science, LUMSA University, Rome 00193, Italy; ${ }^{3}$ Department of Psychology, Sapienza University, \\ Rome 00185, Italy
}

\begin{abstract}
Long-lasting memories of adverse experiences are essential for individuals' survival but are also involved, in the form of recurrent recollections of the traumatic experience, in the aetiology of anxiety diseases (e.g., post-traumatic stress disorder [PTSD]). Extinction-based erasure of fear memories has long been pursued as a behavioral way to treat anxiety disorders; yet, such a procedure turns out to be transient, context-dependent, and ineffective unless it is applied immediately after trauma. Recent evidence indicates that, in both rats and humans, extinction training can prevent the return of fear if administered within the reconsolidation window, when memories become temporarily labile and susceptible of being updated. Here, we show that the reconsolidation-extinction procedure fails to prevent the spontaneous recovery of a remote contextual fear memory in a mouse model of PTSD, as well as the long-lasting behavioral abnormalities induced by traumatic experience on anxiety and in both social and cognitive domains (i.e., social withdrawal and spatial learning deficits). Such a failure appears to be related to the ineffectiveness of the reconsolidation-extinction procedure in targeting the pathogenic process of fear sensitization, a nonassociative component of traumatic memory that causes animals to react aberrantly to harmless stimuli. This indicates fear sensitization as a major target for treatments aimed at mitigating anxiety and the behavioral outcomes of traumatic experiences.
\end{abstract}

[Supplemental material is available for this article.]

Memories of dangerous events are essential for individuals' survival, but are potentially harmful and maladaptive when they cause excessive fear and anxiety. Indeed, long-lasting traumatic fear memories are involved in the pathophysiology of anxiety diseases, such as post-traumatic stress disorder (PTSD). Hence, the pharmacological or behavioral erasure of fearful memories has long been pursued as an effective way to treat anxiety disorders (Gogolla et al. 2009; Kindt et al. 2009; Monfils et al. 2009; Schiller et al. 2010). Pavlovian fear conditioning is one of the most widely used behavioral paradigms for studying the acquisition and retention of fear-related memories in animal models (Pavlov 1927; Goosen and Maren 2001; Hartley and Phelps 2009; Rabinak et al. 2009; Makkar et al. 2010; Pape and Pare 2010; Radulovic and Tronson 2010; Schreurs et al. 2011). In this paradigm, an initially neutral stimulus (conditioned stimulus; CS) is paired with an aversive experience (unconditioned stimulus; US). After CS-US pairing, the presentation of the CS alone is able to trigger the conditional response (CR).

Extinction, whereby the repeated presentation of nonreinforced CS gradually decreases CR, is the simplest way to attenuate the expression of fear memories (Bouton 2004; Wessa and Flor 2007; Archbold et al. 2010; Plendl and Wotjak 2010; Quirk et al. 2010; Storsve et al. 2010; Thompson et al. 2010). It is widely accepted that extinction rather than erasing fear memory involves the formation of a new memory trace (Quirk and Mueller 2008;

\footnotetext{
${ }^{4}$ Corresponding author.
}

E-mail vincenzo.cestari@ipsifar.rm.cnr.it.

Article is online at http://www.learnmem.org/cgi/doi/10.1101//m.2175811.
Pape and Pare 2010). However, the beneficial effects of such a procedure turn out to be temporary and context dependent (Bouton 2004; Myers et al. 2006). Moreover, extinction is only effective if administered in the early aftermath of the traumatic experience (Golub et al. 2009).

An important step forward in the modification of fear memories has come from the discovery that consolidated fear memories become temporarily labile after retrieval and require a new stabilization (reconsolidation) process in order to be restored (Nader et al. 2000; Tronson et al. 2006). Drugs blocking reconsolidation have been found to weaken the original memory and disrupt fear expression (Nader et al. 2000; Nader 2003; Kindt et al. 2009; Taubenfeld et al. 2009; Muravieva and Alberini 2010; Stafford and Lattal 2010). Clinical implications for the treatment of human emotional disorders have been readily recognized, including the possibility of tackling PTSD by erasing fear memories during the reconsolidation process (Monfils et al. 2009; Schiller et al. 2010). However, pharmacological treatments targeting the reconsolidation process in humans have yet to be fully developed, since some are characterized by hard-to-solve toxicity and pharmacodelivery constraints (Nader et al. 2000; Duvarci and Nader 2004; Alberini 2005; Alberini et al. 2006; Lee et al. 2006; Sara and Hars 2006; Doyère et al. 2007; Quirk and Milad 2010).

Recently, a behavioral design has been proposed in which recent (24-h-old) auditory-cued fear memories are destabilized and permanently attenuated by administering the extinction procedure immediately after memory retrieval-i.e., within the reconsolidation window. This approach has been reported as promising considering that it has been applied in both rats 
(Monfils et al. 2009) and humans (Schiller et al. 2010). According to the reconsolidation theory, such a procedure should cause fearful memories to be definitely reinterpreted as safe, thus providing a potentially powerful tool to tackle fear-related symptoms of human psychological disorders (Hartley and Phelps 2009; Monfils et al. 2009; Schiller et al. 2010). However, as noted by Quirk and Milad (2010), it is currently unknown whether the retrieval-extinction method would be effective for modifying fearful memories acquired months or years before the beginning of the extinction training, rather than in the 24 -h period immediately preceding it. These time constraints have to be taken into account when attempting to apply the reconsolidation-extinction procedure to the treatment of anxiety disorders in humans. Indeed, PTSD symptoms related to memories of a traumatic experience can appear months or even years after the trauma (American Psychiatric Association 2000).

Another important aspect that needs to be considered is fear sensitization. Experimental evidence indicates that the expression of fear conditioning is determined by both an associative and a nonassociative memory component: The former refers to the memory for the previously described CS-US pairing, while the latter refers to a sensitization process that increases the animals' responses to harmless stimuli independently from the CS-US contingency (Kamprath and Wotjak 2004). The role of fear sensitization in the development and persistence of PTSD-like symptoms has been recently pointed out (Siegmund and Wotjak 2006, 2007a). Thus, among the procedures that are able to attenuate fear memories, it turns out that extinction acts primarily on the CS-US contingency, leaving fear sensitization relatively intact (Golub et al. 2009). Likewise, the retrievalextinction procedure has been reported to act on the associative component of fear memory, but data concerning its effect on the nonassociative component are still lacking.

On the basis of the above reported studies, we chose to investigate the effectiveness of extinguishing fear memory during the reconsolidation window, but in a model of greater translational relevance to PTSD. A recently established mouse model of PTSD (Siegmund and Wotjak 2007a,b; Pamplona et al. 2011) was used that allows the emergence of increased avoidance of traumarelated stimuli and emotional over-reaction to unspecific "neutral" stimuli, which belong to the three clusters of PTSD symptoms (American Psychiatric Association 2000; Siegmund and Wotjak 2007a). Moreover, this model takes into account the pathological properties of fear incubation showing an increased hyperarousal with the passage of time after the traumatic experience (Siegmund and Wotjak 2007a), when remote traumatic memories are concerned.

Two main issues are addressed: (1) The first is whether the retrieval-extinction procedure is able to persistently attenuate the expression of remote fear memories, and (2) the second is whether an effect of the retrieval-extinction procedure on fear sensitization and long-lasting behavioral outcomes due to traumatic experience can be found.

To address these issues, we used a contextual fear-conditioning paradigm based on the studies by Siegmund and Wotjak $(2007 \mathrm{a}, \mathrm{b})$ describing a mouse model of PTSD in which both the associative and nonassociative components of fear memory were evaluated. In the present research, mice were trained in a neutral context (CS), in which they experienced a painful electric footshock (US). After remote memory retrieval-i.e., re-exposing animals to the context without US administration $29 \mathrm{~d}$ after training-mice were submitted to an extinction training applied within the reconsolidation window. As concerns the interval between retrieval and extinction, a 10-min delay has been reported as the shortest interval to be effective in preventing the return of fear in both rats and humans (Monfils et al. 2009;
Schiller et al. 2010). However, since extinction training usually lasts for longer than $10 \mathrm{~min}$, a combination of retrieval and extinction could be envisaged also in the standard protocols of extinction. Hence, a 10-min interval could be misleading in interpreting the effects induced by either retrieval-extinction coupling or extinction alone on fear expression. For this reason we decided to apply an interval $(1 \mathrm{~h})$ longer than extinction training duration, in which retrieved memories are still susceptible to be updated. Actually, such an interval has been reported to be effective in preventing spontaneous recovery, reinstatement, and renewal in rats submitted to the retrieval-extinction procedure after auditory-cued fear conditioning (Monfils et al. 2009). The effect of the retrieval-extinction procedure was then evaluated with regard to both the associative (contextual) and the nonassociative (sensitization) components of fear memory. Furthermore, the long-lasting outcomes of the procedure were evaluated 1 mo later by testing animals for spontaneous recovery, fear incubation, anxiety levels, social interaction, and spatial learning. These tests have been chosen on the basis of recent advances showing increased anxiety, social withdrawal, and visuo-spatial memory deficits in both animal models of PTSD and human patients (Uddo et al. 1993; Gilbertson et al. 2001; Cohen et al. 2003, 2006, 2011; Louvart et al. 2005; Morgan et al. 2006; Wessa et al. 2006; Kohda et al. 2007; Siegmund and Wotjak 2007a; Kung et al. 2010; Arbisi et al. 2011). Recent studies show the ineffectiveness of the extinction procedure in attenuating fear sensitization (Golub et al. 2009) and suggest that the associative and the nonassociative component of fear memory might be independent of each other, with a key role for the nonassociative component in the onset of PTSD-like symptoms (Siegmund and Wotjak 2007b). Therefore, as a final step, we assessed the differential contribution of the associative and nonassociative components of fear memory to the onset of PTSD-like symptoms by submitting mice to a procedure in which an immediate footshock was administered in order to prevent the CS-US association.

\section{Results}

\section{Retrieval-extinction procedure did not attenuate the expression of remote fear memory}

The first experiment addressed the question as to whether or not the extinction training applied within the reconsolidation window was able to persistently attenuate the expression of remote fear memory.

Three groups of mice were trained in a contextual fear-conditioning paradigm. Twenty-nine days after training, one group of conditioned mice was submitted to a retrieval-extinction procedure (Ret-Ext), while a second group had the extinction training without memory retrieval (Ext). The third group (NoTreat) was neither exposed to memory retrieval nor to extinction training. Figure 1B depicts the amount of freezing levels recorded every 3 min during the retrieval trial and the extinction training.

The extinction training significantly reduced the levels of freezing in both Ret-Ext and Ext mice (Fig. 1B). Statistical analysis (two-way ANOVA) revealed a significant effect of the extinction training $\left(F_{(10,140)}=27.65 ; P<0.0001\right)$ and no differences between groups $\left(F_{(1,14)}=3.93 ; P>0.05\right)$.

Memory for extinction was evaluated one (T1) and 30 (T2) days after extinction training in the contextual test (CTX). Statistical analysis (two-way ANOVA) showed significant effects of between group factor $\left(F_{(2,21)}=4.69 ; P<0.05\right)$, time $\left(F_{(1,21)}=\right.$ $26.14 ; P<0.0001)$, and the interaction $\left(F_{(2,21)}=4.44 ; P<0.05\right)$. Individual post-hoc comparisons revealed a significant $(P<$ 0.05) fear memory reduction in Ret-Ext and Ext mice at T1 
A

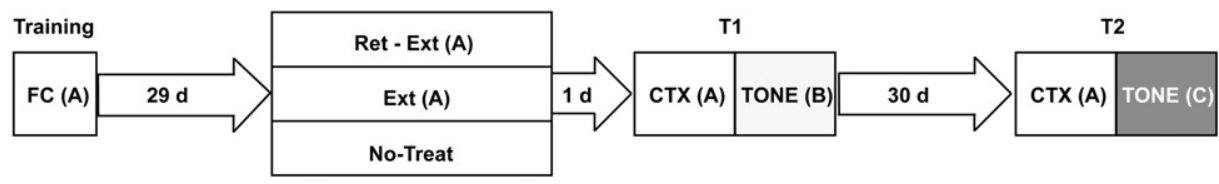

B

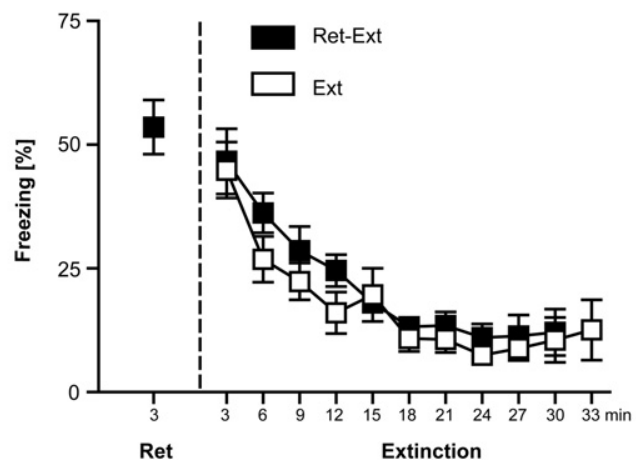

C

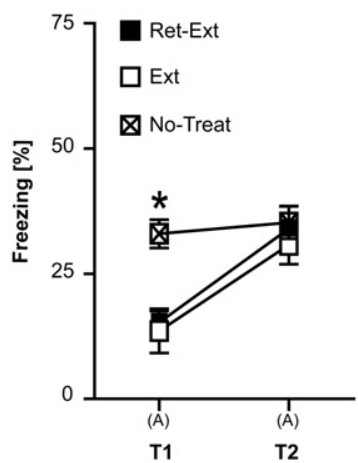

D

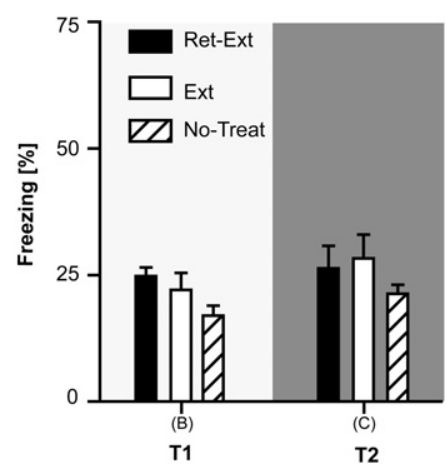

Figure 1. (See also Supplemental Fig. S1.) Effect of reconsolidation-extinction procedure on the expression of remote fear memory. (A) Experimental schedule. Fear-conditioned mice were randomly assigned to three different experimental groups $29 \mathrm{~d}$ after training: Ret-Ext $(n=8)$ mice underwent the retrieval trial (Ret) in conditioning chamber A for $3 \mathrm{~min}$ and then underwent $30 \mathrm{~min}$ of extinction training (Extinction) $1 \mathrm{~h}$ after retrieval in the same chamber; Ext $(n=8)$ mice were submitted to 33 min of extinction training in chamber A; No-Treat $(n=8)$ mice were not exposed to either memory retrieval or to an extinction session. All mice were submitted to a contextual memory test (CTX) in chamber A and to a fear sensitization test (TONE) in chamber B (T1). Thirty days after T1 all mice underwent CTX in chamber A and TONE in chamber C (T2) in order to evaluate spontaneous recovery and fear incubation, respectively. $(B)$ Percentage of freezing responses recorded during retrieval and extinction. $(C, D)$ Percentage of freezing response recorded during $(C)$ contextual $(C T X)$ and $(D)$ fear sensitization (TONE) tests. All data are shown as mean \pm SEM. $\left({ }^{*}\right) P<0.05$ vs. all other groups.

when compared with No-Treat mice. However, this reduction was not persistent, and a spontaneous recovery was evident on the retest at $\mathrm{T} 2$ in which Ret-Ext and Ext mice reached $(P>0.05)$ the levels of freezing showed by No-Treat mice (Fig. 1C).

Fear sensitization was evaluated by exposing Ret-Ext, Ext, and No-treat mice to two new contexts (Context B and Context $\mathrm{C}$, respectively, at T1 and T2) with a neutral tone administration. One-way ANOVA did not reveal significant differences between groups during T1 $\left(F_{(2,21)}=2.68 ; P>0.05\right)$ and T2 $\left(F_{(2,21)}=1.32\right.$; $P>0.05)$, indicating that extinction alone or in combination with memory retrieval did not affect the nonassociative component of fear memory (Fig. 1D). Before tone onset, all mice exposed to new contexts showed the same low levels of freezing (Context B: $F_{(2,21)}=0.45, P>0.05$; Context C: $F_{(2,21)}=1.54, P>0.05$; Supplemental Fig. S1), indicating that the effects we observed were not due to a generalization process.

Anxiety levels, social interaction, and spatial memory were also tested in these groups of mice.

No-Treat, Ret-Ext, and Ext mice tested in the Plus maze showed higher anxiety levels compared with no-shocked (NS) mice. Conditioned mice (No-Treat, Ret-Ext, and Ext) spent significantly less time in open arms (one-way ANOVA: $F_{(3,28)}=4.04 ; P<$ 0.05; Fig. 2A, left) and they showed a significant reduction in the number of crossings to open arms $\left(F_{(3,28)}=3.51 ; P<0.05\right.$; Fig. 2A, right). However, no significant differences in the number of crossings to closed arms $\left(F_{(3,28)}=0.08, P>0.05\right)$ and locomotor activity, calculated as the covered distance $\left(F_{(3,28)}=0.05, P>\right.$ 0.05), were observed among groups (Supplemental Fig. S2A,B).

In the social avoidance/approach test (Fig. 2B) No-treat, RetExt, and Ext mice spent less time in the social side of the apparatus compared with NS mice, as revealed by one-way ANOVA carried out on the social interaction index $\left(F_{(3,28)}=4.23 ; P<0.05\right)$, while no significant differences between groups were found during the first session $\left(F_{(3,28)}=2.35 ; P>0.05\right)$ when the social stimulus was not present. Moreover, no significant differences between groups were observed in the exploratory activity both before (distance: $F_{(3,28)}=0.1, P>0.05$; crossing: $\left.F_{(3,28)}=0.43, P>0.05\right)$ and during (distance: $F_{(3,28)}=0.58, P>0.05$; crossing: $F_{(3,28)}=0.89$, $P>0.05$ ) the social stimulus presentation (Supplemental Fig. S2C,D), suggesting that social withdrawal in this task was not due to a general avoidance behavior.

As concerns spatial learning, all mice submitted to the Morris water maze task showed a significant effect of learning $\left(F_{(17,476)}=\right.$ 11.59; $P<0.0001)$. However, the escape latencies of No-Treat, Ret-Ext, and Ext mice were significantly higher than those observed in NS mice $\left(F_{(3,28)}=3.17 ; P<0.05\right)$ (Fig. 2 C). A similar pattern of results was observed when the swimming distance recorded during the training was considered as the dependent variable (between group factor: $F_{(3,28)}=3.04, P<0.05$; learning factor: $F_{(2,56)}=31.2, P<0.0001$; interaction: $\left.F_{(6,56)}=0.3, P>0.05\right)$ (Supplemental Fig. S2E). Nevertheless, no significant differences between groups were found in the swimming speed (between group factor: $F_{(3,28)}=0.45, P>0.05$; learning factor: $F_{(2,56)}=$ $2.09, P>0.05$; interaction: $F_{(6,56)}=0.37, P>0.05$ ) (Supplemental Fig. S2F), floating (between group factor: $F_{(3,28)}=0.35, P>0.05$; learning factor: $F_{(2,56)}=17.46, P<0.0001$; interaction: $F_{(6,56)}=$ $0.14, P>0.05$ ) (Supplemental Fig. S2G), and time spent near the wall by the animals (between group factor: $F_{(3,28)}=0.7, P>$ 0.05; learning factor: $F_{(2,56)}=10.63, P<0.001$; interaction: $\left.F_{(6,56)}=0.41, P>0.05\right)$ (Supplemental Fig. S2H), thus suggesting that the learning deficit observed in conditioned mice was not due to altered stress-coping strategies.

Taken together, these results indicate that the retrievalsextinction procedure is not an effective treatment for long-lasting consequences of contextual fear memory. Extinction after retrieval of remote contextual fear memory, as well as extinction alone, does not prevent the onset of PTSD-like symptoms (hyperarousal, anxiety, social withdrawal, and memory deficits) 
A

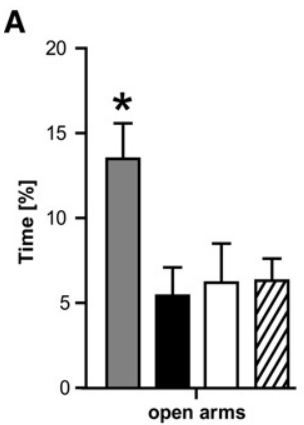

Plus Maze

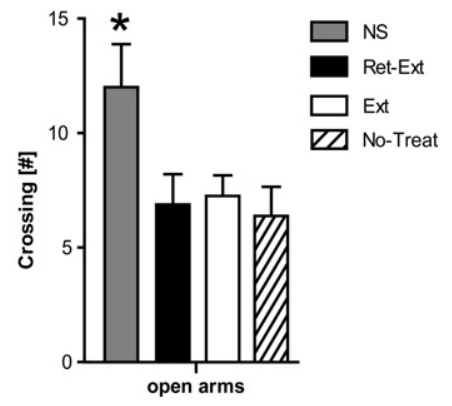

B Social Avoidance/Approach

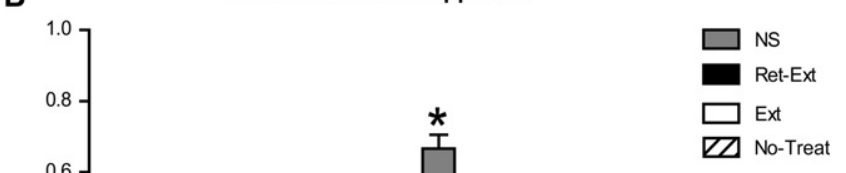

C

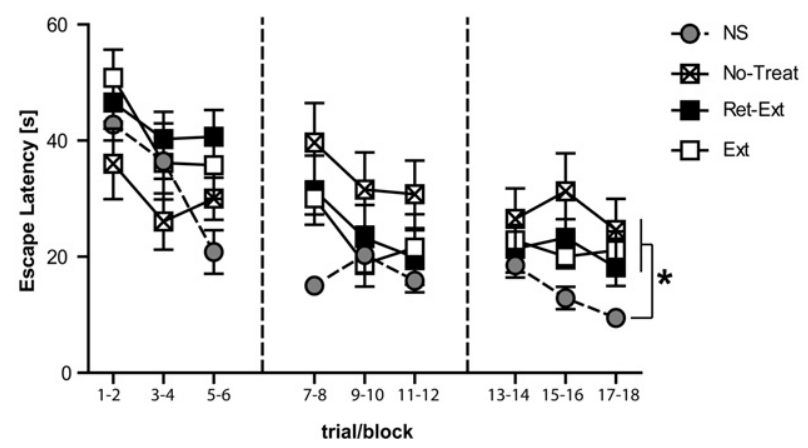

Figure 2. (See also Supplemental Fig. S2.) Fear-conditioned mice (No-treat, Ret-Ext, and Ext) showed higher anxiety levels, social withdrawal, and spatial memory deficits compared with no-shocked control mice (NS, $n=8)$. ( $A$ ) In the Plus Maze, anxiety levels were evaluated as percentage of time spent in open arms (left) and the number of crossings to open arms (right). (B) Social avoidance/approach index was calculated as the ratio of the time spent in social and nonsocial chambers of the apparatus $\left(T_{\text {social }} /\left(T_{\text {social }}+T_{\text {nonsocial }}\right)\right.$. (C) Escape latency is expressed in seconds required to reach the hidden platform in a spatial water maze task (six trials per day; trial/block $1-18$ ). $\left(^{*}\right) P<0.05$ vs. all other groups.

observed in conditioned (No-Treat) mice considered as PTSD models (Siegmund and Wotjak 2007a).

\section{Extinction after a longer retrieval does not attenuate the expression of remote fear memory}

In the previous experiment, we found that extinction after retrieval of remote contextual fear memory did not prevent spontaneous recovery and fear sensitization, as well as behavioral abnormalities induced by fear conditioning. One reason why the retrieval-extinction procedure may be ineffective in attenuating remote contextual fear memory is because of a resistance to reactivation. As suggested by Frankland et al. (2006), fear memories become increasingly stable as they mature and are resistant to disruption induced by post-retrieval administration of reconsolidation blockers. However, a longer retrieval trial can destabilize remote memories, making them susceptible to the amnesic effect of a reconsolidation blocker (Frankland et al. 2006). Thus, it is possible that the extinction-reconsolidation procedure needs a longer duration of retrieval trial to be effective in attenuating remote fear memory. To test this hypothesis, mice were trained, and $29 \mathrm{~d}$ later were re-exposed to the conditioning context for $15 \mathrm{~min}$. As in the previous experiment, animals were submitted to a 30-min extinction training applied $1 \mathrm{~h}$ after the end of the retrieval trial. Contextual memory (CTX) and fear sensitization (Tone) were evaluated one (T1) and 30 (T2) days after extinction. The performance of mice submitted to a longer retrieval before extinction (L-Ret-Ext) was compared with that of conditioned mice that were neither exposed to retrieval nor extinction (No-Treat). Figure 3B depicts the freezing levels recorded every 3 min during the 15-min retrieval trial and the 30-min extinction training. Repeated measure ANOVAs revealed a significant decrement in freezing during both the retrieval trial and the extinction training $\left(F_{(4,28)}=30.76 ; P<0.0001\right.$ and $F_{(9,63)}=3.04 ; P<0.005$, respectively). Overall, the freezing levels recorded in the extinction trial were lower compared with that shown in Experiment 1 , suggesting that this longer duration of re-exposure may start to produce some extinction (Frankland et al. 2006). In the CTX test (Fig. 3C), statistical analysis (two-way ANOVA) showed a significant effect of group $\left(F_{(1,14)}=5.44 ; P<0.05\right)$, time $\left(F_{(1,14)}=\right.$ 5.78; $P<0.05)$ and the interaction between factors $\left(F_{(1,14)}=\right.$ $14.25 ; P<0.01)$. Similar to the results of the Experiment $1, \mathrm{~L}-$ Ret-Ext mice exhibited a significant $(P<0.05)$ reduction in freezing at $\mathrm{T} 1$ that spontaneously recovered $(P>0.05)$ at $\mathrm{T} 2$, reaching the levels shown by No-Treat mice. In the fear sensitization tests (Fig. 3D) one-way ANOVAs carried out on freezing levels recorded during tests revealed no significant differences between groups during tone administration at both $\mathrm{T} 1\left(F_{(1,14)}=0.32 ; P>0.05\right)$ and T2 $\left(F_{(1,14)}=0.76 ; P>0.05\right)$. Before tone onset, all mice exposed to new contexts showed the same low levels of freezing (Context B: $F_{(1,14)}=0.68, P>0.05$; Context C: $F_{(1,14)}=0.62, P>$ 0.05 ) (Supplemental Fig. S3), indicating that the effects we observed were not due to a generalization process.

Taken together these results indicated that extinction training after longer retrieval trials did not prevent spontaneous recovery and did not affect fear sensitization.

\section{Immediate footshock procedure causes the onset of PTSD-like symptoms}

In previous experiments we have shown that extinction training, alone or after retrieval, reduced contextual memory but not fear sensitization at T1, indicating that extinction acted exclusively on the associative component of fear memory. These results, together with other experimental evidence (Siegmund and Wotjak 2006, 2007a,b; Golub et al. 2009), suggest that the nonassociative component of fear memory is accountable for the behavioral abnormalities induced by traumatic experiences. To disentangle the effective role of associative and nonassociative components of fear memory in the onset of PTSD-like symptoms, we exposed mice to an immediate high footshock (S-Hi), in which the associative component was missing (Rosen et al. 1998). Behavioral performance of these mice was compared with that of pain threshold (C/S-PT) and high (C/S-Hi) footshockconditioned mice.

Results shown in Figure 4 indicate that the S-Hi procedure induced fear sensitization but not contextual memory. Statistical analysis (two-way ANOVA) revealed significant differences 

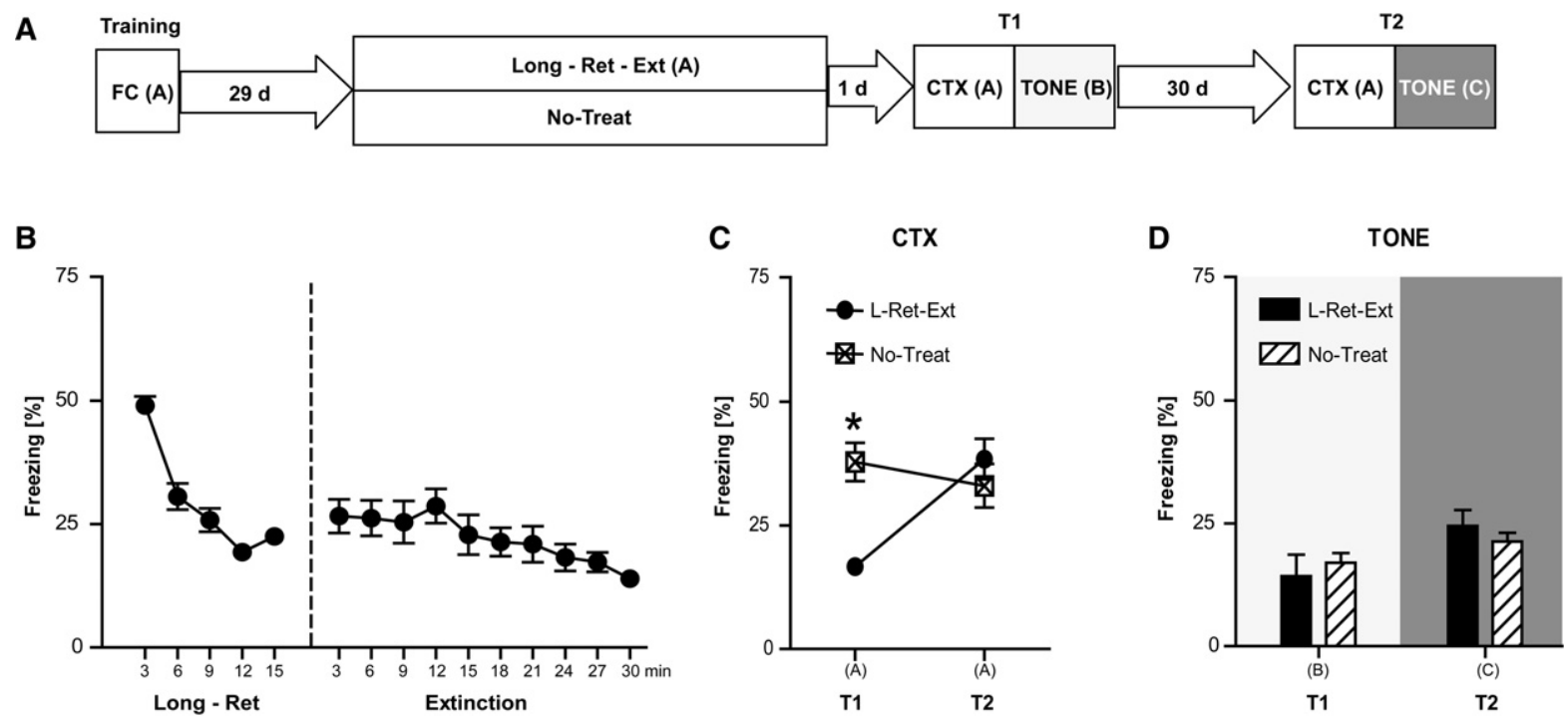

Figure 3. (See also Supplemental Fig. S3.) Effect of extinction after a longer retrieval trial on expression of remote fear memory. $(A)$ Experimental schedule. Fear-conditioned mice were randomly assigned to two different experimental groups $29 \mathrm{~d}$ after training: L-Ret-Ext $(n=8)$ mice underwent a longer retrieval trial (Long-Ret) in conditioning chamber A $(15 \mathrm{~min})$ and then submitted to $30 \mathrm{~min}$ of extinction training (Extinction) $1 \mathrm{~h}$ after retrieval in the same chamber; No-Treat $(n=8)$ mice were not exposed to either memory retrieval or extinction session. All mice were submitted to a contextual memory test (CTX) in chamber A and to a fear sensitization test (TONE) in chamber B (T1). Thirty days after T1, all mice underwent CTX in chamber A and TONE in chamber $C$ (T2) in order to evaluate spontaneous recovery and fear incubation, respectively. (B) Percentage of freezing response recorded during long retrieval and extinction. $(C, D)$ Percentage of freezing response recorded during $(C)$ contextual $(C T X)$ and $(D)$ fear sensitization (TONE) tests. All data are shown as mean \pm SEM. $\left(^{*}\right) P<0.05$ vs. L-Ret-Ext mice.

between groups in the levels of freezing recorded during CTX $\left(F_{(2,24)}=62.32 ; P<0.0001\right)$. In particular, freezing levels of $\mathrm{S}-\mathrm{Hi}$ mice were significantly lower than those displayed by C/S-PT and C/S-Hi mice in both T1 and T2 (Duncan's post-hoc test; $P<$ 0.05) (Fig. 4B). One-way ANOVA carried out on freezing levels recorded during fear sensitization tests (Fig. 4C) showed significant differences between groups in both T1 $\left(F_{(2,24)}=18.75 ; P<\right.$ $0.001)$ and $\mathrm{T} 2\left(F_{(2,24)}=18.93 ; P<0.001\right)$. In these tests the freezing levels displayed by S-Hi mice were statistically undistinguishable $(P>0.05)$ from those of $\mathrm{C} / \mathrm{S}$-Hi mice. Before tone onset, all mice exposed to new contexts showed the same low levels of freezing (Context B: $F_{(2,24)}=1.86, P>0.05$; Context C: $F_{(2,24)}=0.82$, $P>0.05$ ) (Supplemental Fig. S4), indicating that the effects we observed were not due to a generalization process.

When anxiety levels, social interaction, and spatial memory were evaluated (Fig. 5), S-Hi mice showed behavioral profiles identical to those observed in $\mathrm{C} / \mathrm{S}$-Hi mice, while the performances of C/S-PT mice were similar to those shown by no-shocked (NS) mice.

In the plus maze test (Fig. 5A), the time spent in and the number of crossings to open arms was significantly reduced in both $\mathrm{C} / \mathrm{S}$-Hi and S-Hi mice when compared with C/S-PT and NS mice (one-way ANOVAs: $F_{(3,31)}=5.18 ; P<0.01$ and $F_{(3,31)}=$ 4.94; $P<0.01$, respectively). However, no significant differences in the number of crossings to closed arms $\left(F_{(3,31)}=0.09, P>\right.$ $0.05)$ and locomotor activity, calculated as the covered distance $\left(F_{(3,31)}=0.04, P>0.05\right)$, were observed among groups (Supplemental Fig. S5A,B).

In the social avoidance/approach test (Fig. 5B), C/S-Hi and S-Hi mice spent lesser time (one-way ANOVA: $F_{(3,31)}=8.51 ; P<$ 0.001 ) in the social side of the apparatus compared with C/S-PT and NS mice. No significant differences between groups were found during the first session when the social stimulus was not present $\left(F_{(3,31)}=0.84 ; P>0.05\right)$. Moreover, no significant differences between groups were observed in the exploratory activity recorded both before (distance: $F_{(3,31)}=0.43, P>0.05$; crossing:
$\left.F_{(3,31)}=0.14, P>0.05\right)$ and during (distance: $F_{(3,31)}=0.69, P>$ 0.05 ; crossing: $\left.F_{(3,31)}=0.82, P>0.05\right)$ the social stimulus presentation (Supplemental Fig. S5C,D), suggesting that social withdrawal in this task was not due to a general avoidance behavior.

As concerns spatial learning (Fig. 5C), C/S-Hi and S-Hi showed significantly higher latencies to reach the platform in the Morris water maze compared with those displayed by C/ S-PT and NS mice (two-way ANOVA: $F_{(3,31)}=4.61 ; P<0.01$ for group factor; $F_{(17,527)}=6.63 P<0.0001$ for learning factor; and $F_{(51,527)}=1.93 ; P<0.001$ for the interaction). A similar pattern of results was observed when the swimming distance recorded during the training was considered as the dependent variable (between group factor: $F_{(3,31)}=8.92, P<0.005$; learning factor: $F_{(2,62)}=39.5, P<0.0001$; interaction: $\left.F_{(6,62)}=0.96, P>0.05\right)$ (Supplemental Fig. S5E). Nevertheless, no significant differences between groups were found in the swimming speed (between group factor: $F_{(3,31)}=0.69, P>0.05$; learning factor: $F_{(2,62)}=$ 1.07; $P>0.05$; interaction: $F_{(6,62)}=0.68, P>0.05$ ) (Supplemental Fig. S5F), floating (between group factor: $F_{(3,31)}=0.28, P>0.05$; learning factor: $F_{(2,62)}=22.82, P<0.001$; interaction: $F_{(6,62)}=$ $0.79, P>0.05$ ) (Supplemental Fig. S5G), and time spent near the wall by the animals (between group factor: $F_{(3,31)}=1.23$, $P>0.05$; learning factor: $F_{(2,62)}=28.79, P<0.001$; interaction: $F_{(6,62)}=2.63, P>0.05$ ) (Supplemental Fig. S5H), thus suggesting that the learning deficit observed in conditioned mice was not due to altered stress-coping strategies.

\section{Discussion}

The main result of the present study is that extinction training applied within the reconsolidation window of a remote contextual fear memory did not persistently attenuate the expression of fear in a mouse model of PTSD.

A common approach to the clinical treatment of PTSD focuses on the facilitation of fear extinction through exposure therapy, in which the repeated safe exposure to trauma reminders 
A

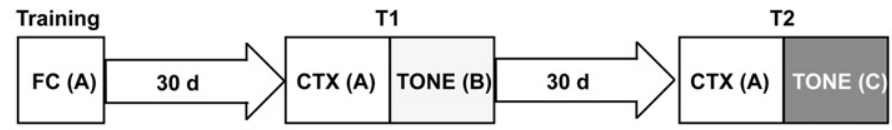

B

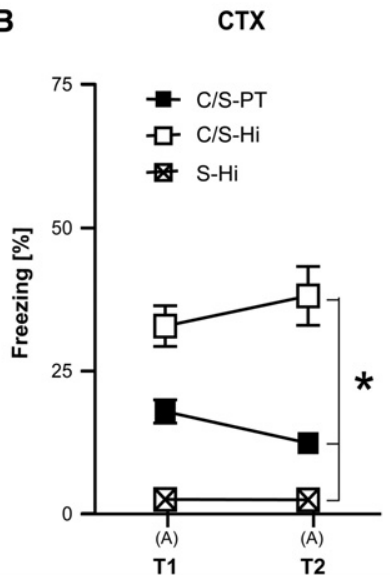

Figure 4. (See also Supplemental Fig. S4.) An immediate footshock procedure induces fear sensitization but not contextual memory. (A) Experimental schedule. Mice were randomly assigned to three different groups: C/S-Hi $(n=9)$ received a high electric footshock $(0.7 \mathrm{~mA})$; C/S-PT $(n=9)$ received a pain threshold electric footshock; $\mathrm{S}-\mathrm{Hi}(n=9)$ received an immediate high electric footshock $(0.7 \mathrm{~mA})$ and was immediately removed from the apparatus. Thirty days after training (T1), all mice were submitted to a contextual memory test (CTX) in conditioning chamber $\mathrm{A}$ and to a fear sensitization test (TONE) in chamber B. Thirty days after T1, all mice underwent CTX in chamber A and TONE in chamber C (T2) in order to evaluate spontaneous recovery and fear incubation, respectively. $(B, C)$ Percentage of freezing response recorded during $(B)$ contextual $(C T X)$ and $(C)$ fear sensitization (TONE) tests. All data are shown as mean \pm SEM. $\left({ }^{*}\right) P<0.05$. might represent an interesting model of specific phobias, its usefulness in anxiety disorders like post-traumatic stress disorder, resulting from contextual conditioning, and second order operant conditioning processes, is limited. Second, the investigators found that the shortest efficient interval between retrieval and the onset of extinction training for permanent memory erasure was $10 \mathrm{~min}$. This, however, should then apply to most of the currently used extinction training protocols, which last for longer than $10 \mathrm{~min}$ and, thus, may be regarded as a combination of retrieval (i.e., the beginning of extinction training) and extinction training (i.e., nonreinforced CS exposure toward the end of extinction training) as well.

In the present work a main goal was to verify whether the effect of the reconsolidation-extinction procedure could be extended to remote fear memories in a more clinically relevant context. To this purpose, we used a fear conditioning procedure in which the involvement of both the associative and nonassociative components could be investigated in remote fear memory. Indeed, as highlighted by Siegmund and Wotjak (2007a), the role played by these two components and by fear incubation should be taken carefully into account to obtain a valid animal model of PTSD.

(CS-noUS) changes the CS-US contingency expectation. That is, CSs that predicted danger after conditioning are reinterpreted as safe after extinction (Hartley and Phelps 2009). However, extinction does not permanently change the CS-US expectation, and spontaneous recovery of fear expression is frequently observed (Myers and Davis 2002, 2007; Bouton 2004).

Within the reconsolidation theory framework, a number of animal studies have shown that a pharmacological blockade of reconsolidation is possible (Przybyslawski and Sara 1997; Nader et al. 2000; Duvarci and Nader 2004; Alberini 2005; Alberini et al. 2006; Lee et al. 2006; Sara and Hars 2006; Doyère et al. 2007). However, from a clinical perspective this approach is still limited since some drugs used in animal studies, with exceptions such as propranolol (Brunet et al. 2008; Kindt et al. 2009), are not safe for humans (Przybyslawski and Sara 1997; Nader et al. 2000; Duvarci and Nader 2004; Alberini 2005; Alberini et al. 2006; Lee et al. 2006; Sara and Hars 2006; Doyère et al. 2007; Quirk and Milad 2010).

To overcome these limitations, a behavioral procedure has recently been proposed in which an extinction training applied within the reconsolidation window is able to persistently attenuate the expression of recent (1-d-old) fear memories and prevent spontaneous recovery in both rats and humans (Monfils et al. 2009; Schiller et al. 2010). It should be noted, though, that clinical observations refer to long-lasting behavioral outcomes of traumatic experience. Thus, time constraints have to be carefully considered in claiming the reconsolidation-extinction procedure as an effective strategy to treat anxiety disorders in humans (Quirk and Milad 2010). Moreover, other constraints about the procedure designed by Monfils et al. (2009) and Schiller et al. (2010) need to be considered. First, in the latter studies an elementary-cued fear conditioning paradigm was used. While the proposed paradigm
The results of our experiments showed that extinction after retrieval of remote fear memory reduced contextual memory, but did not prevent spontaneous recovery.

It has to be noted that, as they mature, memories become increasingly stable and immune to destabilization induced by retrieval (Milekic and Alberini 2002; Suzuki et al. 2002; Pedreira and Maldonado 2003; Frankland et al. 2006). Notably, Frankland et al. (2006) reported that in mice a 15-min-long re-exposure to the original conditioning context was necessary for remote contextual fear memory to be reactivated. We considered the possibility that the duration of the retrieval session in Experiment 1 (3 min) was too short to cause fear memories to become labile and to be reconsolidated. To rule out this possibility, in Experiment 2 we replicated, in an independent group of conditioned mice, the reconsolidation-extinction procedure, increasing the duration of the retrieval session up to $15 \mathrm{~min}$. Data from this experiment were comparable to those previously obtained with a 3-min retrieval trial. The only difference was a lower extinction performance, which suggests that the longer re-exposure duration (15 min) may start to produce some extinction (Frankland et al. 2006). Significantly, we found that even with such a modified procedure spontaneous recovery was not prevented. On the other hand, shorter retrieval sessions have been previously shown to effectively reactivate both recent and remote contextual fear memory in rats (Debiec et al. 2002; Lee et al. 2004). Therefore, the possibility that a 3 -min reactivation session could be too long and that such a period could engage an extinction process cannot be ruled out. However, a 3-min reactivation session in a contextual fear conditioning paradigm appears to engage a pattern of molecular mechanisms involved in the reconsolidation process but not in the extinction process, while a distinct molecular pattern linked to extinction appears in a 30-min 
A

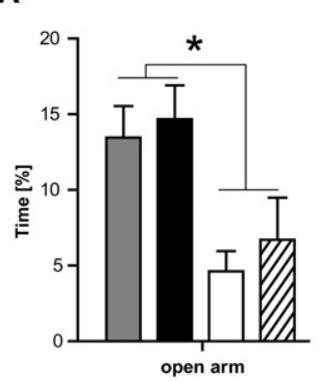

Plus Maze

B
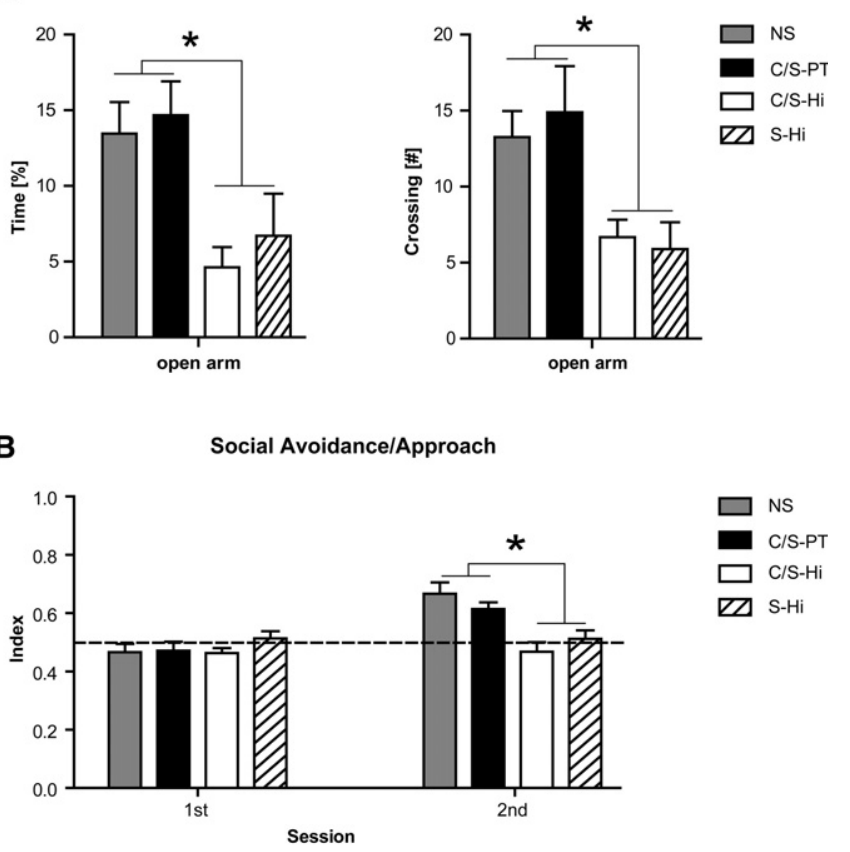

C

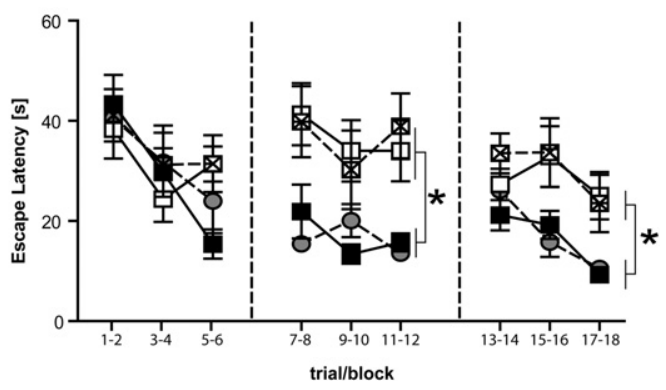

Figure 5. (See also Supplemental Fig. S5.) An immediate footshock procedure induces anxiety behavior, social withdrawal, and spatial memory deficits. Performances of shocked mice (C/S-Hi; C/S-PT; S-Hi) were compared with those of no-shocked control mice (NS, $n=8)$. (A) In the Plus Maze, anxiety levels were evaluated as percentage of time spent in open arms (left) and number of crossings to open arms (right). $(B)$ Social avoidance/approach index was calculated as the ratio of the time spent in social and nonsocial chambers of the apparatus ( $T_{\text {social }} /$ ( $\left.T_{\text {social }}+T_{\text {nonsocial }}\right)$. (C) Escape latency is expressed in seconds required to reach the hidden platform in a spatial water maze task (six trials per day; trial/block 1-18). (*) $P<0.05$.

reactivation session (Mamiya et al. 2009). Further, Bustos et al. (2009) showed that in rats the extinction process in the contextual fear conditioning appears to begin with a reactivation session longer than a 3-min period.

Taken together, our results confirm that the age of the fear memory is an important factor when choosing treatments for anxiety disorders. While the retrieval-extinction procedure could be an effective strategy to attenuate recent traumatic memories, it does not seem suitable to tackle PTSD, in which the role of remote memories has to be taken into account (Quirk and Milad 2010).

A further aspect that needs to be considered is that shown in recent studies by Kamprath and Wotjak (2004) who have demonstrated that in the acquisition of conditioned fear the associative component is accompanied by a nonassociative one, namely, a sensitization process. This idea is consistent with the dual-process theory (Groves and Thompson 1970) according to which "every stimulus that evokes a behavioral response has two properties: it elicits a response and influences the state of the organism" (page 440), i.e., its general level of excitation, arousal, activation, tendency to respond, etc. Evidence indicates that although the general state of the organism can influence the tendency to respond, the associative and nonassociative components are largely independent of each other (Siegmund and Wotjak 2007b) and seem to involve different neurobiological substrates (Gewirtz et al. 1998). If fear sensitization is strongly involved in the pathomechanisms of emotional diseases (Foa et al. 1992; Charney et al. 1993; Antelman 1998; Shalev et al. 2000; Kamprath and Wotjak 2004; Siegmund and Wotjak 2006), then promising strategies for the treatment of PTSD should entail targeting of fear sensitization.

Our data are in agreement with previous findings showing that late extinction training (1 mo after acquisition) is ineffective in reducing fear sensitization (Golub et al. 2009). Additionally, we found that extinction failed to prevent anxiety behaviors, social withdrawal, and spatial learning deficits induced by fear conditioning.

Further, to our knowledge this is the first study showing that the reconsolidation-extinction procedure is ineffective in reducing fear sensitization. Hence, the failure of the retrieval-extinction procedure to attenuate remote contextual fear memory could be due to its inefficiency in affecting fear sensitization. At the theoretical level, both memory retrieval and extinction have been claimed to involve only the associative component of the traumatic experience (Golub et al. 2009). This would mean that the retrieval of fear memory triggered by the mere re-exposure to the conditioning context (i.e., in the absence of US) might only be able to reactivate the fear experience partially when stable remote memories are involved (Frankland et al. 2006). It is important to note that the latter cannot be considered a general rule, since a need for US presentation during reactivation has been observed when appetitive reconsolidation is involved (Lee and Everitt 2008; Taubenfeld et al. 2010). However, it has also to be considered that US presentation during retrieval is not always applicable, especially when aversive fear memories, like those characterizing PTSD, are considered.

The interpretation we propose here regarding the failure of the retrieval-extinction procedure in attenuating the expression of remote contextual fear memory takes into account the informative properties of the CS, which signals reinforcement in the acquisition phase and nonreinforcement during retrieval-extinction (Capaldi 1966). Indeed, during CS presentation in retrieval and extinction, animals learn a new rule in which the CS does not predict the US (Redish et al. 2007; Chan et al. 2010). Fear originally linked to the CS, however, could outlive the "extinction rule" as decontextualized emotional content related to the nonassociative component.

This raises questions about the actual role of fear sensitization in the onset of PTSD-like symptoms. Recently, Siegmund and Wotjak (2007b) have shown that the blockade of hippocampal activity reduces contextual fear memory but not fear sensitization in a mouse model of PTSD, suggesting that the nonassociative component is independent from the trauma-related contextual memory (Siegmund and Wotjak 2007b). Consistently, our third experiment demonstrated that an immediate-shock conditioning procedure, in which the formation of contextual memory was prevented by minimizing the amount of time animals spent in the conditioning box before footshock administration, induced fear sensitization and long-lasting abnormal behaviors as observed in fully trained mice. This suggests that fear sensitization could be the main factor accountable for the 
onset of PTSD-like symptoms. In this context it has to be noted that Pamplona et al. (2011), using a shock intensity (1.5 mA) considerably higher than that used in our work $(0.7 \mathrm{~mA})$, have recently found that contextual fear conditioning and subsequent fear incubation led to a generalized avoidance behavior in mice submitted to a conditioned odor task. However, in our experiments, animals submitted to a high electric footshock $(0.7 \mathrm{~mA})$ showed an exploratory activity in the plus maze and social avoidance tasks, as well as stress-coping strategies in the Morris water maze, comparable to that of control mice. Moreover, no differences in the freezing level recorded before tone presentation in the sensitization test were observed among the different groups of mice. Therefore, the increased anxiety levels, social withdrawal, and spatial learning deficit observed in our groups of mice submitted to a high electric footshock $(0.7 \mathrm{~mA})$ appear not to be correlated with a general avoidance state. Considering the work by Pamplona et al. (2011), a role for the shock intensity in the onset of a general avoidance state could therefore be taken into account.

Altogether, our results show that an extinction training administered within the memory reconsolidation window, when traces are supposed to be destabilized and updated, does not attenuate the expression of remote contextual fear memory in mice. In particular, the reconsolidation-extinction procedure fails to prevent spontaneous recovery of fear-related behavior and fear incubation, as well as long-lasting behavioral abnormalities (i.e., aberrant anxiety, social withdrawal, and spatial memory deficits) induced by traumatic experience. Most importantly, we found the reconsolidation-extinction procedure to spare the pathogenic process of fear sensitization, regardless of the age of traumatic memories or the duration of retrieval.

On the whole, our results strongly suggest that targeting of fear sensitization is a major goal to be pursued in the effort to improve behavioral strategies aimed at mitigating long-lasting outcomes of traumatic experience.

\section{Materials and Methods}

\section{Animals}

A total of $83 \mathrm{C} 57 \mathrm{BL} / 6 \mathrm{~N}$ male mice (Charles River), aged $8 \mathrm{wk}$ and weighing 25-30 g were used in these experiments. Upon arrival, the mice were housed in groups of four in standard breeding cages $(21 \times 21 \times 12 \mathrm{~cm})$ and kept in a 12-h light/dark cycle (lights were on from 07:00 to 19:00 h) at a constant temperature of $21^{\circ} \mathrm{C}$, and given food and water ad libitum. The research in this study was conducted according to Italian national laws and regulations on the use of animals in research and NIH guidelines on animal care. Maximum care was taken to minimize the number of animals used and to minimize their suffering.

\section{Fear conditioning}

Fear conditioning experiments were performed in mouse conditioning chambers connected to a control unit in which the intensity of the house light, the auditory stimulus, and the scrambled footshock delivered from the grid metal floor could be set up (TSE, Bad Homburg, Germany).

Experiments were carried out in three different chambers in order to evaluate contextual fear memory and fear sensitization. The first chamber (Context A; $26 \times 22 \times 18 \mathrm{~cm}$ ) was a rectangular box made of blue Plexiglas with a grid metal floor lighted with a white-tensor lamp (19 Lux); after each experimental trial this cage was cleaned with an ethanol solution $(30 \% \mathrm{v} / \mathrm{v})$. The second chamber (Context B; diameter $=20 \mathrm{~cm}$ ) was a cylindrical transparent box with wood shavings on the floor lighted with a redtensor lamp (18 Lux); after each experimental session this cage was cleaned with an acetic acid solution $(1 \% \mathrm{v} / \mathrm{v})$. The third chamber (Context C; $26 \times 22 \times 18 \mathrm{~cm}$ ) was a rectangular box made of black Plexiglas with a gray plastic floor lighted with a blue-tensor lamp (57 Lux) and the smell was modified with a lemon essence; after each experimental trial this cage was cleaned with ethanol solution $(10 \% \mathrm{v} / \mathrm{v})$. All chambers were located in a sound-insulated box $(52 \times 52 \times 65 \mathrm{~cm})$ equipped with a microvideo camera mounted at the top of the apparatus. Freezing behavior, considered as the complete absence of voluntary movements, was recorded and considered as a fear index.

\section{Elevated plus maze}

The plus maze was carried out in a gray Plexiglas elevated maze with four arms $30-\mathrm{cm}$ long and $5-\mathrm{cm}$ wide, extending from a central starting platform. While two facing arms were closed by gray walls (15-cm high), the other two arms were left opened. The experimental room was lighted with four white-tensor lamps (40W) and the light intensity recorded in the apparatus was 29 Lux for closed arms and 58 Lux for open arms. Animals were placed in the center of the apparatus and allowed to explore for $5 \mathrm{~min}$. Behavior was videotaped and the time spent in and the number of crossings to the open arms and closed arms, as well as the covered distance, were analyzed using the EthoVision software (Noldus information Technology).

\section{Social avoidance/approach test}

The social avoidance/approach test was carried out in a rectangular box made of transparent Plexiglas $(41 \times 70 \times 28 \mathrm{~cm})$ surrounded by walls $(28-\mathrm{cm}$ high) made of the same material, with wood shavings as bedding. The experimental room was lighted with four lamps (40W) and the light intensity recorded in the apparatus was 43 Lux. For the social avoidance/approach test the box was divided in three interconnected chambers of equal size. Each lateral chamber contained a transparent Plexiglas cylinder $(8 \mathrm{~cm}$ in diameter) with small holes $(0.5 \mathrm{~cm}$ in diameter), in which a juvenile C57BL/6N male mouse (stimulus) was placed during the test. Prior to the start of each test, one of the end chambers was arbitrarily designated as the "social side" (the side into which the stimulus mouse would be introduced), and the other end chamber was designated as the "nonsocial side." At the beginning of each test, the test mouse was placed in the central chamber of the apparatus and was allowed to freely explore all three chambers during a 5-min acclimation period ( $1^{\text {st }}$ session). At the end of the initial 5-min period, the tops of both the Plexiglas cylinders were removed simultaneously; the stimulus mouse was placed in the cylinder on the side that had been designated the "social side" and then the tops were simultaneously placed back on the Plexiglas cylinders. The time that the test mouse spent in each of the three chambers was again measured over the next 5 min $\left(2^{\text {nd }}\right.$ session). At the end of each test, the mice were removed from the apparatus. Behavior was videotaped by a video camera placed above the apparatus and the time spent in the chambers was analyzed by using the EthoVision software (Noldus information Technology). A social avoidance/approach index was calculated as the ratio of the time spent in social and nonsocial chambers according to the formula: $\mathrm{T}_{\text {social }} /\left(\mathrm{T}_{\text {social }}+\mathrm{T}_{\text {nonsocial }}\right)$. Moreover, the total number of crossings among chambers and the distance covered by the animals in the apparatus were analyzed to assess their general exploratory activity.

\section{Morris water maze}

The Morris water maze was carried out in a circular swimming pool $1.3 \mathrm{~m}$ in diameter, filled with opaque water, at a temperature of $25^{\circ} \pm 1^{\circ} \mathrm{C}$ and located in a room containing prominent extramaze cues. The apparatus was lighted with four tensor-lamps (20W) located on the floor at the corners of the room, and the light intensity was recorded at the water level of 8 Lux. A hidden, $15-\mathrm{cm}$ diameter platform was used. Training consisted of 18 trials (six trials per day) lasting a maximum of $60 \mathrm{sec}$, with an intertrial interval of $30 \mathrm{~min}$. The start position was changed for each trial with the platform left in the same position. Behaviors were evaluated by EthoVision software (Noldus information Technology). 


\section{Statistical analysis}

Data obtained in all experiments were analyzed by using one- or two-way ANOVAs. Individual between-group comparisons, where appropriate, were carried out by the Duncan multiple range test or the PLSD Fisher test. All data are presented as mean \pm SEM. Statistical significance was accepted if $P<0.05$.

\section{Experiment 1: Effect of the retrieval-extinction procedure} on the expression of remote fear memory.

The experimental schedule is shown in Figure 1A.

\section{Experimental groups}

Mice were randomly assigned to the Retrieval-Extinction (RetExt; $n=8$ ), the Extinction (Ext; $n=8$ ), or No-treatment (NoTreat; $n=8$ ) conditions.

\section{Fear acquisition, memory retrieval, and extinction procedure}

On day 1 all mice were trained in Context A. After $198 \mathrm{sec}$ of acclimatization, a footshock of $2 \mathrm{sec}$ was delivered from the grid metal floor (US; $0.7 \mathrm{~mA}$ ). Animals remained in the shock chamber for another 60 sec before they were returned to their home cage.

Twenty-nine days after training, mice were submitted to the following procedures:

Ret-Ext mice were submitted to a single trial (3 min) of memory retrieval in context A without footshock administration. One hour after retrieval, i.e., within the reconsolidation window, extinction was carried out by placing animals in context A for 30 min without footshock administration.

Ext mice were submitted to context A for 33 min without footshock administration.

No-Treat mice, considered as a control group, were neither exposed to memory retrieval or extinction session.

\section{Contextual fear memory and sensitized fear tests}

One day after the extinction session (for both Ret-Ext and Ext groups), or $30 \mathrm{~d}$ after training (for No-Treat group), mice were tested in context A for 3 min to evaluate contextual fear memory. Four hours after the contextual fear memory test, mice were placed in a new context $B$ in which a neutral tone $(80 \mathrm{~dB}, 9 \mathrm{kHz})$ was continuously delivered during the last $3 \mathrm{~min}$ of a 6 -min period to evaluate fear sensitization (Siegmund and Wotjak 2007a).

\section{Spontaneous recovery and fear incubation tests}

Thirty days after memory tests, spontaneous recovery was evaluated by re-exposing animals to context A. Fear sensitization, as a function of incubation time, was evaluated by placing mice in a new context $\mathrm{C}$, in which the tone $(80 \mathrm{~dB}, 9 \mathrm{kHz})$ was delivered during the last $3 \mathrm{~min}$ of a 6 -min period.

\section{Additional behavioral tests}

After fear incubation tests, consequences of fear memory on anxiety levels, social interaction, and spatial memory were evaluated by testing Ret-Ext, Ext, and No-Treat mice in the plus maze, social avoidance/approach test, and Morris water maze. An additional group of nonshocked (NS, $n=8$ ) mice was used as a control.

\section{Experiment 2: Effect of extinction after a longer retrieval trial on expression of remote fear memory}

The experimental schedule is shown in Figure 3A.

\section{Experimental groups}

Mice were randomly assigned to the Long-Retrieval-Extinction (L-Ret-Ext; $n=8$ ) or No-treatment (No-Treat; $n=8$ ) conditions.

\section{Fear acquisition, memory retrieval, and extinction procedure}

On day 1 all mice were submitted to the same training procedure described in Experiment 1. Twenty-nine days after training mice were submitted to the following procedures:
L-Ret-Ext mice were submitted to a 15-min retrieval trial in context A without footshock administration. One hour after retrieval, extinction was carried out by placing animals in context A for 30 min without footshock administration.

No-Treat mice, considered as a control group, were neither exposed to memory retrieval nor an extinction session.

\section{Contextual fear memory and sensitized fear tests}

Both L-Ret-Ext and No-Treat mice were tested with the same experimental schedule described in Experiment 1.

\section{Spontaneous recovery and fear incubation tests}

Both L-Ret-Ext and No-Treat mice were tested with the same experimental schedule described in Experiment 1.

\section{Experiment 3: Effect of an immediate footshock procedure on fear sensitization}

The experimental schedule is shown in Figure 4A.

\section{Experimental groups}

Mice were randomly assigned to three different training procedures: (1) training with a high footshock $(\mathrm{C} / \mathrm{S}-\mathrm{Hi} ; n=9)$; (2) training with a pain threshold footshock (C/S-PT; $n=9)$; (3) training with an immediate high footshock (S-Hi; $n=9)$.

\section{Fear acquisition}

$\mathrm{C} / \mathrm{S}$-Hi mice were placed in the conditioning chamber for $198 \mathrm{sec}$ and then shocked with a high footshock ( $0.7 \mathrm{~mA}, 2 \mathrm{sec})$. Animals remained in the shock chamber for another $60 \mathrm{sec}$ before they were returned to their home cage.

$\mathrm{C} / \mathrm{S}$-PT mice were placed in the conditioning chamber for $198 \mathrm{sec}$ and then shocked with a pain threshold footshock. Animals remained in the shock chamber for another $60 \mathrm{sec}$ before they were returned to their home cage. Pain threshold to footshock was individually adjusted and defined as the lowest shock intensity at which an animal's hind foot left the metal floor.

$\mathrm{S}$-Hi mice were placed in the conditioning chamber, shocked with a high footshock $(0.7 \mathrm{~mA}, 2 \mathrm{sec})$ and immediately removed from the apparatus.

\section{Contextual fear memory and sensitized fear tests}

Similarly to previous experiments, remote contextual fear memory was assessed $30 \mathrm{~d}$ after training in context A, while fear sensitization was evaluated in context $\mathrm{B}$ with tone administration.

\section{Contextual memory and fear incubation tests}

Thirty days after contextual and sensitization tests, mice were retested in context A for contextual memory assessment and in context $\mathrm{C}$ with tone administration for evaluation of fear incubation.

\section{Additional behavioral tests}

After fear incubation tests, consequences of fear memory on anxiety levels, social interaction, and spatial memory were evaluated by testing C/S-Hi, C/S-PT, and S-Hi mice in the plus maze, social avoidance/approach test, and Morris water maze. An additional group of nonshocked (NS, $n=8$ ) mice was used as control.

\section{Acknowledgments}

We thank Francesca D'Alessandro for technical assistance. This work was supported by FILAS in the frame of a collaboration agreement with Regione Lazio—Distretto Tecnologico delle Bioscienze.

\section{References}

Alberini CM. 2005. Mechanisms of memory stabilization: Are consolidation and reconsolidation similar or distinct processes? Trends Neurosci $\mathbf{2 8}$ : 51-56. 
Alberini CM, Milekic MH, Tronel S. 2006. Memory: Mechanisms of memory stabilization and de-stabilization. Cell Mol Life Sci 63: 999-1008.

American Psychiatric Association. 2000. Diagnostic and statistical manual of mental disorders. 4th ed. American Psychiatric Association, Washington, DC.

Antelman SM. 1998. Time-dependent sensitization as the cornerstone for a new approach to pharmacotherapy-drugs as foreign stressful stimuli. Drug Dev Res 14: 1-30.

Arbisi PA, Polusny MA, Erbes CR, Thuras P, Reddy MK. 2011. The Minnesota Multiphasic Personality Inventory-2 Restructured Form in National Guard soldiers screening positive for posttraumatic stress disorder and mild traumatic brain injury. Psychol Assess 23: 203-214.

Archbold GEB, Bouton ME, Nader K. 2010. Evidence for the persistence of contextual fear memories following immediate extinction. Eur J Neurosci 31: 1303-1311.

Bouton ME. 2004. Context and Behavioral Processes in Extinction. Learn Mem 11: 485-494.

Brunet A, Orr SP, Tremblay J, Robertson K, Nader K, Pitman RK. 2008. Effect of post-retrieval propranolol on psychophysiologic responding during subsequent script-driven traumatic imagery in post-traumatic stress disorder. J Psychiatr Res 42: 503-506.

Bustos SG, Maldonado H, Molina VA. 2009. Disruptive effect of midazolam on fear memory reconsolidation: Decisive influence of reactivation time span and memory age. Neuropsychopharmacology 34: 446-457.

Capaldi EJ. 1966. Partial reinforcement: A hypothesis of sequential effects. Psychol Rev 73: 459-477.

Chan WY, Leung HT, Westbrook RF, McNally GP. 2010. Effects of recent exposure to a conditioned stimulus on extinction of Pavlovian fear conditioning. Learn Mem 17: 512-521.

Charney DS, Deutch AY, Krystal JH, Southwick SM, Davis M. 1993. Psychobiologic mechanism of post-traumatic stress disorder. Arch Gen Psychiatry 50: 295-305.

Cohen H, Zohar J, Matar M. 2003. The relevance of differential response to trauma in an animal model of posttraumatic stress disorder. Biol Psychiatry 53: 463-473.

Cohen H, Kaplan Z, Matar M, Loewenthal U, Kozlovsky N, Zohar J. 2006. Anisomycin, a protein synthesis inhibitor, disrupts traumatic memory consolidation and attenuates posttraumatic stress response in rats. Biol Psychiatry 60: 767-776.

Cohen H, Kaplan Z, Koresh O, Matar MA, Geva AB, Zohar J. 2011. Early post-stressor intervention with propranolol is ineffective in preventing posttraumatic stress responses in an animal model for PTSD. Eur Neuropsychopharmacol 21: 230-240.

Debiec J, LeDoux JE, Nader K. 2002. Cellular and systems reconsolidation in the hippocampus. Neuron 36: $527-538$.

Doyère V, Debiec J, Monfils MH, Schafe GE, LeDoux JE. 2007. Synapse-specific reconsolidation of distinct fear memories in the lateral amygdale. Nat Neurosci 10: 414-416.

Duvarci S, Nader K. 2004. Characterization of fear memory reconsolidation. J Neurosci 24: 9269-9275.

Foa EB, Zinbarg R, Rothbaum BO. 1992. Uncontrollability and unpredictability in post-traumatic stress disorder: An animal model. Psychol Bull 112: 218-238.

Frankland PW, Ding HK, Takahashi E, Suzuki A, Kida S, Silva AJ. 2006. Stability of recent and remote contextual fear memory. Learn Mem 13: $451-457$

Gewirtz JC, McNish KA, Davis M. 1998. Lesions of the bed nucleus of the stria terminalis block sensitization of the acoustic startle reflex produced by repeated stress, but not fear-potentiated startle. Prog Neuropsychopharmacol Biol Psychiatry 22: 625-648.

Gilbertson MW, Gurvits TV, Lasko NB, Orr SP, Pitman RK. 2001. Multivariate assessment of explicit memory function in combat veterans with Posttraumatic Stress Disorder. J Trauma Stress 14: 413-432.

Gogolla N, Caroni P, Luthi A, Herry A. 2009. Perineuronal nets protect fear memories from erasure. Science 325: 1258-1261.

Golub Y, Mauch CP, Dahlhoff M, Wotjak CT. 2009. Consequences of extinction training on associative and non-associative fear in a mouse model of Posttraumatic Stress Disorder (PTSD). Behav Brain Res 205: $544-549$.

Goosen KA, Maren S. 2001. Contextual and auditory fear conditioning are mediated by the lateral, basal, and central amygdaloid nuclei in rats. Learn Mem 8: 148-155.

Groves PM, Thompson RF. 1970. Habituation: A dual-process theory. Psychol Rev 77: 419-450.

Hartley CA, Phelps EA. 2009. Changing fear: The neurocircuitry of emotion regulation. Neuropsychopharmacology 35: 136-146.

Kamprath K, Wotjak CT. 2004. Nonassociative learning processes determine expression and extinction of conditioned fear in mice. Learn Mem 11: $770-786$.

Kindt M, Soeter M, Vervliet B. 2009. Beyond extinction: Erasing human fear responses and preventing the return of fear. Nat Neurosci 12: 256-258.
Kohda K, Harada K, Kato K, Hoshino A, Motohashi J, Yamaji T, Morinobu S, Matsuoka N, Kato N. 2007. Glucocorticoid receptor activation is involved in producing abnormal phenotypes of single-prolonged stress rats: A putative post-traumatic stress disorder model. Neuroscience 148: $22-33$

Kung JC, Chen TC, Shyu BC, Hsiao S, Huang AC. 2010. Anxiety- and depressive-like responses and c-fos activity in preproenkephalin knockout mice: Oversensitivity hypothesis of enkephalin deficit-induced posttraumatic stress disorder. J Biomed Sci 17: 29-42.

Lee JL, Everitt BJ. 2008. Reactivation-dependent amnesia for appetitive memories is determined by the contingency of stimulus presentation. Learn Mem 15: 390-393.

Lee JL, Everitt BJ, Thomas KL. 2004. Independent cellular processes for hippocampal memory consolidation and reconsolidation. Science 304: 839-843.

Lee JL, Milton AL, Everitt BJ. 2006. Reconsolidation and extinction of conditioned fear: Inhibition and potentiation. J Neurosci 26: 10051-10056.

Louvart H, Maccari S, Ducrocq F, Thomas P, Darnaudèry M. 2005. Long-term behavioural alterations in female rats after a single intense footshock followed by situational reminders. Psychoneuroendocrinology 30: $316-324$.

Makkar SR, Zhang SQ, Cranney J. 2010. Behavioral and neural analysis of GABA in the acquisition, consolidation, reconsolidation, and extinction of fear memory. Neuropsychopharmacology 35: 1625-1652.

Mamiya N, Fukushima H, Suzuki A, Matsuyama Z, Homma S, Frankland PW, Kida S. 2009. Brain region-specific gene expression activation required for reconsolidation and extinction of contextual fear memory. J Neurosci 29: 402-413.

Milekic MH, Alberini CM. 2002. Temporally graded requirement for protein synthesis following memory reactivation. Neuron 36: 521-525.

Monfils MH, Cowansage KK, Klann E, LeDoux JE. 2009.

Extinction-Reconsolidation boundaries: Key to persistent attenuation of fear memories. Science 324: 951-955.

Morgan CA 3rd, Doran A, Steffian G, Hazlett G, Southwick SM. 2006. Stress-induced deficits in working memory and visuo-constructive abilities in Special Operations soldiers. Biol Psychiatry 60: 722-729.

Muravieva EV, Alberini CM. 2010. Limited efficacy of propranolol on the reconsolidation of fear memories. Learn Mem 17: 306-313.

Myers KM, Davis M. 2002. Behavioral and neural analysis of extinction. Neuron 36: $567-584$.

Myers KM, Davis M. 2007. Mechanisms of fear extinction. Mol Psychiatry 12: $120-150$.

Myers KM, Ressler KJ, Davis M. 2006. Different mechanisms of fear extinction dependent on length of time since fear acquisition. Learn Mem 13: 216-223.

Nader K. 2003. Memory traces unbound. Trends Neurosci 26: 65-72.

Nader K, Schafe GE, LeDoux JE. 2000. Fear memory require protein synthesis in the amygdala for reconsolidation after retrieval. Nature 406: $722-726$.

Pamplona FA, Henes K, Micale V, Mauch CP, Takahashi RN, Wotjak CT. 2011. Prolonged fear incubation leads to generalized avoidance behavior in mice. J Psychiatr Res 45: 354-360.

Pape HC, Pare D. 2010. Plastic synaptic networks of the amygdala for the acquisition, expression, and extinction of conditioned fear. Physiol Rev 90: $419-463$.

Pavlov IP. 1927. Conditioned Reflex: an investigation of the physiological activity of the cerebral cortex. Oxford University Press, London, UK.

Pedreira ME, Maldonado H. 2003. Protein synthesis subserves reconsolidation or extinction depending on reminder duration. Neuron 38: $863-869$.

Plendl W, Wotjak CT. 2010. Dissociation of within- and between-session extinction of conditioned fear. J Neurosci 30: 4990-4998.

Przybyslawski J, Sara SJ. 1997. Reconsolidation of memory after its reactivation. Behav Brain Res 84: 241-246.

Quirk GJ, Mueller D. 2008. Neural mechanisms of extinction learning and retrieval. Neuropsychopharmacology 33: 56-72.

Quirk GJ, Milad MR. 2010. Neuroscience: Editing out fear. Nature 463: $36-37$.

Quirk GJ, Paré D, Richardson R, Herry C, Monfils MH, Schiller D, Vicentic A. 2010. Erasing fear memories with extinction training. I Neurosci 30: 14993-14997.

Rabinak CA, Orsini CA, Zimmerman JM, Maren S. 2009. The amygdala is not necessary for unconditioned stimulus inflation after Pavlovian fear conditioning in rats. Learn Mem 16: 645-654.

Radulovic J, Tronson NC. 2010. Molecular specificity of multiple hippocampal processes governing fear extinction. Rev Neurosci 21: $1-17$.

Redish AD, Jensen S, Johnson A, Kurth-Nelson Z. 2007. Reconciling reinforcement learning models with behavioral extinction and renewal: Implications for addiction, relapse, and problem gambling. Psychol Rev 114: 784-805. 
Rosen JB, Fanselow MS, Young SL, Sitcoske M, Maren S. 1998. Immediate-early gene expression in the amygdala following footshock stress and contextual fear conditioning. Brain Res 796: 132-142.

Sara S, Hars B. 2006. In memory of consolidation. Learn Mem 13: $515-521$.

Schiller D, Monfils MH, Raio CM, Johnson DC, LeDoux JE, Phelps EA. 2010. Preventing the return of fear in humans using reconsolidation update mechanisms. Nature 463: 49-53.

Schreurs BG, Smith-Bell CA, Burhans LB. 2011. Unpaired extinction: Implications for treating post-traumatic stress disorder. J Psychiatr Res 45: 638-649.

Shalev AY, Peri T, Brandes D, Orr SP, Pitman RK. 2000. Auditory startle response in trauma survivors with post-traumatic stress disorder: A prospective study. Am J Psychiatry 157: 255-261.

Siegmund A, Wotjak CT. 2006. Toward an animal model of posttraumatic stress disorder. Ann N Y Acad Sci 1071: 324-334.

Siegmund A, Wotjak CT. 2007a. A mouse model of posttraumatic stress disorder that distinguishes between conditioned and sensitised fear. J Psychiatr Res 41: 848-860.

Siegmund A, Wotjak CT. 2007b. Hyperarousal does not depend on trauma-related contextual memory in an animal model of Posttraumatic Stress Disorder. Physiol Behav 90: 103-107.

Stafford JM, Lattal KM. 2010. Direct comparisons of the size and persistence of anisomycin-induced consolidation and reconsolidation deficits. Learn Mem 16: 494-503.

Storsve AB, McNally GP, Richardson R. 2010. US habituation, like CS extinction produces a decrement in conditioned fear responding that is NMDA dependent and subject to renewal and reinstatement. Neurobiol Learn Mem 93: 463-471.
Suzuki A, Josselyn SA, Frankland PW, Masushige S, Silva AJ, Kida S. 2002. Memory reconsolidation and extinction have distinct temporal and biochemical signatures. J Neurosci 24: 4787-4795.

Taubenfeld SM, Riceberg JS, New AS, Alberini CM. 2009. Preclinical assessment for selectively disrupting a traumatic memory via postretrieval inhibition of glucocorticoid receptors. Biol Psychiatry 65: $249-257$.

Taubenfeld SM, Muravieva EV, Garcia-Osta A, Alberini CM. 2010. Disrupting the memory of places induced by drugs of abuse weakens motivational withdrawal in a context-dependent manner. Proc Natl Acad Sci 107: 12345-12350.

Thompson BM, Baratta MV, Biedenkapp JC, Rudy JW, Watkins LR, Maier SF. 2010. Activation of the infralimbic cortex in a fear context enhances extinction learning. Learn Mem 17: 591-599.

Tronson NC, Wieseman SL, Olausson P, Taylor JR. 2006. Bidirectional behavioural plasticity of memory reconsolidation depends on amygdalar protein kinase. Nat Neurosci 9: 167-169.

Uddo M, Vasterling JJ, Brailey K, Sutker PB. 1993. Memory and attention in combat-related post traumatic stress disorder (PTSD). J Psychopathol Behav Assess 15: 43-52.

Wessa M, Flor H. 2007. Failure of extinction of fear responses in Post-Traumatic Stress Disorder: Evidence from second order conditioning. Am J Psychiatry 164: 1684-1692.

Wessa M, Jatzko A, Flor M. 2006. Retrieval and emotional processing of traumatic memories in posttraumatic stress disorder: Peripheral and central correlates. Neuropsychologia 44: 1683-1696.

Received February 18, 2011; accepted in revised form May 31, 2011. 


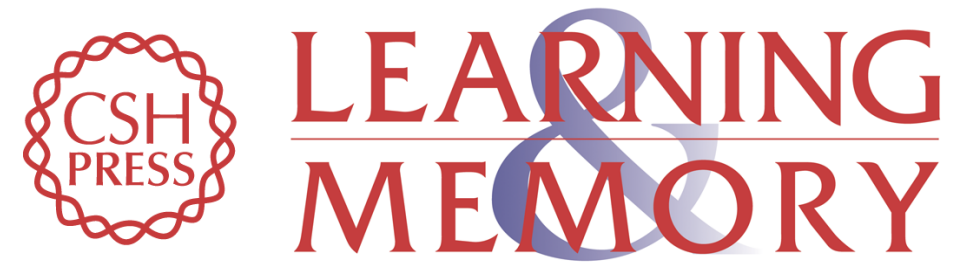

\section{Extinction after retrieval: Effects on the associative and nonassociative components of remote contextual fear memory}

Marco Costanzi, Sara Cannas, Daniele Saraulli, et al.

Learn. Mem. 2011, 18:

Access the most recent version at doi:10.1101//m.2175811

Supplemental
Material http://learnmem.cshlp.org/content/suppl/2011/07/12/18.8.508.DC1

References This article cites 74 articles, 20 of which can be accessed free at: http://learnmem.cshlp.org/content/18/8/508.full.html\#ref-list-1

License

Email Alerting Receive free email alerts when new articles cite this article - sign up in the box at the Service top right corner of the article or click here. 